\title{
How do gender and inchargeness interact to affect equity in lab group interactions?
}

\author{
Sophia M. Jeon, ${ }^{1}$ Z. Yasemin Kalender, ${ }^{1}$ Eleanor C. Sayre, ${ }^{2}$ and N. G. Holmes ${ }^{1}$ \\ ${ }^{1}$ Laboratory of Atomic and Solid State Physics, Department of Physics, Cornell University, Ithaca, NY, 14850 \\ ${ }^{2}$ Department of Physics, Kansas State University, Manhattan, KS, 66506
}

In physics lab groups, students experience a wide range of equitable and inequitable interactions. After observing videos of students collaborating in an introductory physics lab, we defined that an equitable group is one in which every student's bids are heard by their peers. We developed a methodology to characterize different lab groups by tracking students' bid exchanges and assessing their levels of inchargeness. The analysis of equitable and inequitable groups showed that lab groups where one student is in charge can be equitable, as long as each group member's opinions are acknowledged. We also found that gender and inchargeness do not sufficiently predict the equity of student groups. Based on these results, we argue that students that are in charge use their inchargeness to make their groups either equitable or inequitable. Future work will explore whether additional variables interact with inchargeness to predict levels of equity in group work. 


\section{INTRODUCTION}

Instructional physics labs are typically interactive learning environments, but research has shown that student interactions can be a source of inequity in their learning [e.g. 14]. To understand the wide range of equitable and inequitable interactions among students, we build on a methodology to characterize the equity of student lab groups through bids and the notion of inchargeness [5]. Here, we use the term "inchargeness" to refer to the degree to which a person controls the conversation $[6,7]$, as related to their position in the group via positioning theory [8]. Inchargeness does not refer to a single person necessarily being in charge. Multiple students can exhibit inchargeness at once, and one student may exhibit different levels of inchargeness at different times. A person who controls the conversation more than others, however, can be considered generally in charge. Because prior research has found inequitable gendered patterns in participation in lab activities $[2,3,9,10]$, our research seeks to understand the relation between inchargeness, equity, and gender.

\section{THEORETICAL BACKGROUND}

One may define equity in learning environments in multiple ways [11]. Here, we work from Rodriguez et al.'s notion of equity of fairness, whereby all students benefit equally from the learning experience [11]. In group work, that means that students should have equal opportunities to participate [12] with "shared authority and power in driving group activity" [13, p.1]. In more open-ended labs, power dynamics and shared authority are particularly salient, and students use their agency to design their own experiments and make experimentation decisions [2]. For example, students must make a range of decisions including choosing equipment, selecting proper analysis tools, determining sources of uncertainties, or interpreting results. In decision-making, students can make bids (i.e., statements or suggestions) to steer the group decisions [13]. That is, students with inchargeness can direct the progress and content of the discussion [7].

Prior research measured inchargeness in small-groups by counting various student statements such as questions asked and commands given [14]. Previous studies suggest that equal distribution of inchargeness is required for groups to be equitable $[6,15]$. In this work, however, we argue that equal inchargeness is not a necessary condition for equity. That is, we define an equitable group as one in which every student's bids are heard and acknowledged by their peers. In what follows, we will present evidence for our first claim:

Claim \#1: Lab groups where one student is clearly in charge can still be equitable.

One might expect that our first claim requires specific conditions; that is, there may be particular characteristics of a person in charge that dictate whether the group will be equitable or inequitable. For example, students may be in charge through different types of authoritative expressions, such as "epistemic" or "positional" authorities [16]. Alternatively, the size of the group [17], competitiveness of the settings [17], status of group members (e.g., high status "perceived academic ability and popularity" [18]) may also impact how a student's inchargeness leads a group to be equitable or inequitable. The literature also highlights that equity in group activities may depend on the gender composition of the group. For example, groups where female students are underrepresented in the group have been found to be inequitable [4, 19]. In physics labs, specifically, mixed-gender groups have been found to be inequitable as students divide tasks along gender lines $[2,3,9,10]$. In this work, however, we find evidence that gender is not a necessary variable for predicting group equity:

\section{Claim \#2: Gender and inchargeness do not seem to sufficiently predict the equity of a lab group.}

To test these two claims, we observed six groups of students in multiple sessions of an introductory, calculus-based mechanics lab course. We evaluated the equity of the group and students' levels of inchargeness by tracking their bids, and we detected qualitative markers for inchargeness $[6,15]$. We sought patterns between gender and inchargeness in equitable and inequitable groups to test our two claims.

\section{METHODS}

The participants of this study were undergraduate students in a calculus-based introductory mechanics course intended for physics majors and minors at a major research university. The course was approximately $20 \%$ women and had an entirely male teaching team. Students self-identified their gender on an in-class survey. The lab associated with this course is non-traditional, in that students engage in relatively openended investigations to develop experimentation skills. The lab activities were designed to promote frequent collaboration in making decisions about the investigations (e.g., developing a research question, selecting equipment, and presenting results to the class). Students work in groups of two or three and typically choose their own group mates.

\section{A. Case selection}

We first identified two groups to analyze: one that was interpreted as equitable and one as inequitable. The interpretation was based on the researcher's perspective from watching the group's interactions before coding. We developed claims based on the coding analysis (described below) and then deliberately selected new cases to try to refute our tentative claims. In total, we analyzed eight different groups (six groups of three and two pairs). For this work, we restricted our analysis only to the groups of three to evaluate the role of gender balances on equity and inchargeness. 


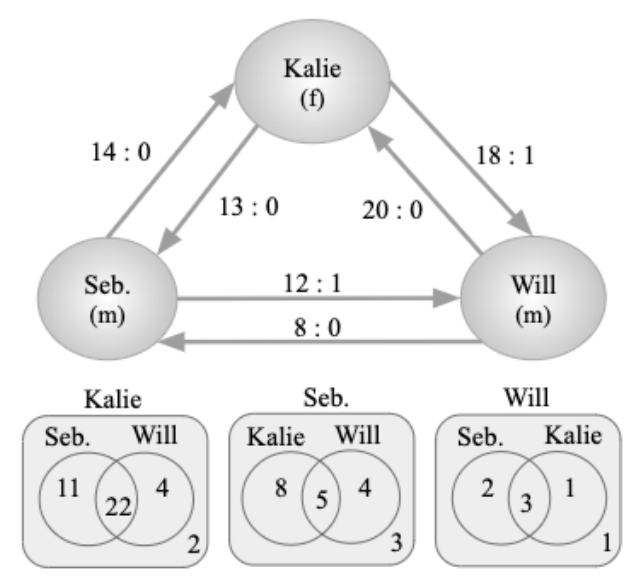

(a) Group E1's bid exchange diagrams. This group is equitable because students acknowledged most of each other's bids, with the number of non-acknowledgments only reaching at most 3 .
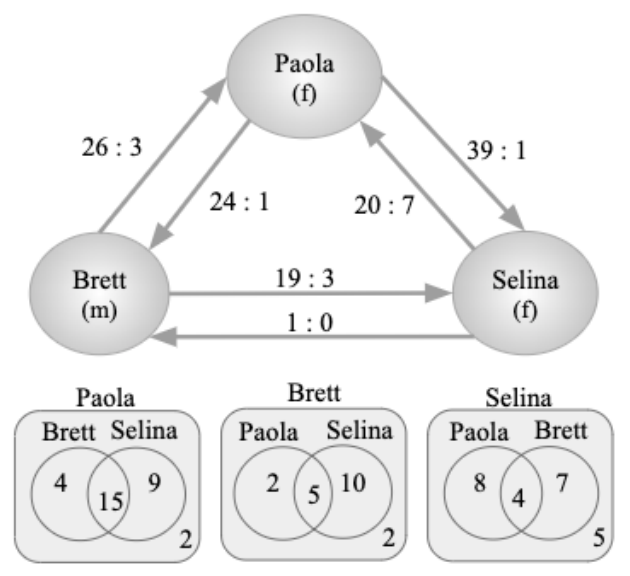

(b) Group I1's bid exchange diagrams. This group is inequitable because seven of Selina's 27 bids were not acknowledged by Paola in their 1-1 bid exchange, and five of Selina's group-directed bids were also not acknowledged.

FIG. 1: Bid exchange diagrams for (a) Group E1 and (b) Group I1. The 1-1 bid diagram (top) shows the ratios of bids acknowledged to not acknowledged between each pair of students. The sum of the two numbers is the total number of bids made from one student to the other. Student gender is noted as female (f) and male (m). The group bid Venn diagrams

(bottom) show the number of group-directed bids that were uniquely or collectively acknowledged by the students.

\section{B. Bid analysis and evaluating equity}

As students collaborate in lab groups, they verbally or nonverbally acknowledge or follow-through with the bids of their peers. We define bids as statements or questions that request that their partners consider an idea or complete a task, specifically to make progress in their activity. A list of the types of bids we considered is shown in Table I.

TABLE I: Types of bids included in the analysis.

\begin{tabular}{|c|c|c|}
\hline Bid Type & Description & Example \\
\hline Prompt & $\begin{array}{l}\text { A question or statement } \\
\text { that directs the flow of } \\
\text { discourse }\end{array}$ & $\begin{array}{l}\text { "What do you want to do?", } \\
\text { or "Want to do that again?" }\end{array}$ \\
\hline Command & $\begin{array}{l}\text { A statement that directs } \\
\text { the behavior of the lab } \\
\text { partners }\end{array}$ & $\begin{array}{l}\text { "You should probably } \\
\text { write down..." }\end{array}$ \\
\hline Suggestion & $\begin{array}{l}\text { An idea or plan put for- } \\
\text { ward for consideration }\end{array}$ & $\begin{array}{l}\text { "We can calculate the beat } \\
\text { frequency..." }\end{array}$ \\
\hline Opinion & $\begin{array}{l}\text { A thought or judgment } \\
\text { about the investigation }\end{array}$ & $\begin{array}{l}\text { "I think we need more } \\
\text { weights" }\end{array}$ \\
\hline
\end{tabular}

To identify students' bids, we first transcribed the audio of the students' interactions in the lab. We then identified all bids based on the criteria in Table I. We also identified whether the bids were acknowledged by the group. Bid acknowledgements included verbal responses to the bids as well as gestures that indicated acknowledgement (such as nodding or following-through with the bid). Non-acknowledgements of bids included a lack of verbal response and gestures, and dismissals of the bids.

We then generated bid exchange diagrams, which represent the numbers of bids exchanged in one-on-one interactions between students and in group-wide interactions (examples shown in Fig. 1a and 1b). The 1-1 bid diagrams show the number of bids made by one student to the other, indicated as a ratio between the number of bids acknowledged to the number of bids not acknowledged. For example, in Fig. 1a, Sebastian directs 14 bids to Kalie and she acknowledges all of them (i.e., does not acknowledge zero of them), whereas Kalie directs 19 bids to Will and he acknowledges 18 of them (i.e., does not acknowledge one). The group bid Venn diagrams represent the bids that each student directed to the entire group, as opposed to an individual student. These diagrams show 1) the number of group-directed bids that each student uniquely acknowledged, 2) the number of bids that all students acknowledged, and 3) the number of bids that no student acknowledged. We differentiated these two kinds of bid exchanges to account for the ways that the group-wide interactions do not require all members to acknowledge the bids; that is, as long as one student hears the group-directed bid, the bid exchange is considered equitable. Inequity, then, is represented by the number of bids that no student in the group heard nor acknowledged.

For each directional, one-on-one interaction (from student A to student B), we calculated the ratio of the number of bids heard to the total number of bids made, $H / T$. We then calculated the average $H / T$ for each group, by averaging across all possible directional pairs (student $\mathrm{A}$ to student $\mathrm{B}$, student B to student A, student A to student $\mathrm{C}$, etc.). 
We used the bid diagrams to evaluate whether the group was equitable or inequitable. We defined an equitable group as one where everyone is heard. Thus, inequitable groups would be ones where individual students have bids that are not acknowledged by their peer(s). This would also be represented by relatively low average values of $H / T$. Large standard deviations of $H / T$ would also indicate inequity, in that individual pairs may have different values of $H / T$.

\section{Measuring inchargeness}

Inchargeness relates primarily to the degree to which a person controls the conversation [6], as related to their position in the group [8]. A student may be in charge if they are at the center of the bid exchanges; that is, they make and receive many of the bids, and many of their bids are acknowledged by their peers. Additional signs of inchargeness include explaining the group's progress to the teaching assistant (TA) and taking on particular roles in the investigation. We also provide information regarding their seating arrangements, as a possible variable for understanding the bid exchanges.

\section{RESULTS}

Before synthesizing across groups, we will explore two cases in detail (Fig. 1). These cases particularly illustrate our two claims: that one person clearly in charge can create an equitable group, and that gender and inchargeness do not seem to sufficiently predict equity.

\section{A. Group E1: The equitable trio}

In Group E1, Kalie, Sebastian, and Will, one female and two male students, work on a pendulum lab at the start of the semester. Their bid exchange diagram, shown in Figure 1a, indicates that the students acknowledge almost all of the bids. Kalie makes the highest number of bids in both 1-1 and group interactions (32 and 39), and all bids except two are acknowledged by her groupmates in 1-1 bid exchanges. Furthermore, she receives the most 1-1 bids from her groupmates (34), suggesting that she is the center of the bid exchanges. Will and Sebastian make a similar number of total bids (28 and 26, respectively), they each have one bid not acknowledged, though Will receives more bids (30) than Sebastian (21).

Additional evidence from the videos suggests that Kalie, overall, is generally in charge of the group. For example, Kalie makes twice as many explanations to the TA as her groupmates. She also makes many suggestions (bids) to Will and Sebastian, as they carry out the data analysis and note taking, respectively. In terms of the seating arrangement, Kalie is seated on the outer end of the lab table. Because she is the center of bid exchange despite being relatively far away from one of her groupmates (and she acknowledges all of her groupmates' bids), we infer that Kalie has the highest level of inchargeness. The group appears to be equitable, overall, however, given that nearly everyone's bids are heard.

\section{B. Group I1: The inequitable trio}

In Group I1, Paola, Selina, and Brett, two female and one male students, work on a similar pendulum lab as Group E1. In the bid exchanges, as shown in Fig. 1b, Paola makes the highest number of bids (65 and 30) and all but two of them are acknowledged by the students in both 1-1 and group interactions. In contrast, Selina only directs one bid to Brett, and seven of her 27 bids to Paola are not acknowledged in 1-1 interactions. Five of Selina's group-directed bids are not acknowledged by her partners. Brett makes 29 to Paola and 21 to Selina, and each of them do not acknowledge three of his bids. The overwhelming number of unacknowledged bids, as well as the imbalance of bids made between pairs, indicates that this group is inequitable.

Paola appears to be the center of bid exchanges, as she makes (65) and receives (56) the most bids in 1-1 interactions. Compared to Group E1, Group I1's seating arrangement may have been responsible for Paola being the center of the bid exchanges. Paola is seated between Selina and Brett, with Brett by the outer side of the table. Brett makes 10 explanations to the TA, while Paola converses with the TA 7 times. From the video, Paola also contributes significantly to the progress of the experiment. With respect to roles, Brett and Paola both lead data collection and analysis, while Selina mainly works on the lab notes.

Considering these bid exchanges and descriptive aspects of their interactions, we conclude that Paola has the highest level of inchargeness, with Brett being the second most in charge of the group and Selina being the least in charge. In this case, Paola's inchargeness relates to the group being inequitable, as she does not acknowledge the most bids (10).

\section{Synthesizing across cases}

We performed similar analyses to those above for four additional groups, as shown in Table II. The equitable groups, as defined, all have relatively high ratios of bids heard to total bids (mean $H / T$ ) compared to the inequitable groups. Interestingly, the standard deviations of the $H / T$ ratios are also more than two times smaller than those for the inequitable groups. This suggests that the inequities are not a result of all students not hearing each other - rather, sub-pairs within the trios may be equitable while the group is inequitable overall.

We also find that male-majority and female-majority groups are both represented in equitable and inequitable groups. However, all of the equitable groups have a female student as most in charge. This result initially suggested to us that gender and inchargeness interact to make a group equitable - that is, a female student needs to be in charge for the group to be equitable. However, Group I1 provided a conflicting case: a female student was in charge and the group was inequitable. This contradictory data point suggests that additional variables, besides gender, are important for understanding how inchargeness relates to equity of lab groups. That is, it appears that students vary in how they handle their inchar- 
geness; some seem to use it as an opportunity to engage equitably with all group members, while some do not, or cannot, capitalize on this opportunity.

TABLE II: Summary of the bid analyses for six groups. The student in bold has the highest inchargeness, and student gender is noted as female (f) and male (m). $H / T$ is the ratio of the number of bids heard to the total bids made from one student to the other (shown as the mean and standard deviation across six possible exchanges for each group).

\begin{tabular}{|c|c|c|c|c|}
\hline $\begin{array}{l}\text { Group } \\
\#\end{array}$ & $\begin{array}{l}\text { Group } \\
\text { bers }\end{array}$ & $\begin{array}{l}\text { H/T, Mean } \\
\text { (SD) }\end{array}$ & $\begin{array}{l}\text { Gender } \\
\text { Balance }\end{array}$ & Equity \\
\hline E1 & $\begin{array}{l}\text { Kalie (f), Sebas- } \\
\operatorname{tian}(\mathrm{m}), \& \text { Will } \\
(\mathrm{m})\end{array}$ & $\begin{array}{l}0.967 \\
(0.038)\end{array}$ & $\mathrm{M}>\mathrm{F}$ & Equitable \\
\hline E2 & $\begin{array}{l}\text { Janelle (f), } \\
\text { Charles (m), \& } \\
\text { Veronica (f) }\end{array}$ & $\begin{array}{l}0.986 \\
(0.025)\end{array}$ & $\mathrm{M}<\mathrm{F}$ & Equitable \\
\hline E3 & $\begin{array}{l}\text { Paola (f), Sean } \\
(\mathrm{m}), \text { \& Derek }(\mathrm{m})\end{array}$ & $\begin{array}{l}0.951 \\
(0.056)\end{array}$ & $\mathrm{M}>\mathrm{F}$ & Equitable \\
\hline I1 & $\begin{array}{l}\text { Paola (f), Brett } \\
(\mathrm{m}), \text { \& Selina (f) }\end{array}$ & $\begin{array}{l}0.905 \\
(0.096)\end{array}$ & $\mathrm{M}<\mathrm{F}$ & Inequitable \\
\hline $\mathrm{I} 2$ & $\begin{array}{l}\text { Peter (m), Bob } \\
(\mathrm{m}), \& \text { Sandra (f) }\end{array}$ & $\begin{array}{l}0.910 \\
(0.129)\end{array}$ & $\mathrm{M}>\mathrm{F}$ & Inequitable \\
\hline I3 & $\begin{array}{l}\text { Garrett (m), } \\
\text { Mark (m), \& } \\
\text { Selina (f) }\end{array}$ & $\begin{array}{l}0.876 \\
(0.161)\end{array}$ & $\mathrm{M}>\mathrm{F}$ & Inequitable \\
\hline
\end{tabular}

\section{DISCUSSION}

In this study, we presented evidence for two claims about the conditions of an equitable group and the interactions between gender and inchargeness in lab group equity.

Our first claim was that students can use their inchargeness to make their groups more equitable, such as by acknowledging their peers, or less equitable, such as by ignoring the bids of their peers. Therefore, the concept of higher inchargeness does not necessarily refer to 'bossing around' or 'dictating ideas,' leading to inequity [6,15]. Rather, higher inchargeness can refer to having a higher number of interactions with group members to coordinate and conduct activities. This is exemplified by Group E1, where although Kalie takes on a managerial role while Will and Sebastian carry out the data analysis and write lab notes, respectively, the group is still equitable. Thus, an individual with higher inchargeness can still make successful bids to delegate the progress of the experiment in an equitable way. In contrast, Group I1 divide tasks such that each student has an independent role: Paola performs most of the data analysis, Selina takes on the lab notes, and Brett works with Paola to collect the data. Previous work recommends students take on distinct roles for the group to be "well-functioning" or equitable [4, 20], from which we may have predicted that Group I1 should be equitable. Future work should clarify how students' inchargeness interacts with the roles they take on and rotate throughout the lab, related to the experimental tasks or group management, to impact the equity of the group.

We also considered the groups' gender compositions in the relation between student inchargness and group equity. Our first case, Group E1, had 1 female and 2 male students. Although previous research states that groups are likely to be inequitable if minority students are outnumbered by majority students [4, 19-21], we found that Kalie had equitable interactions with Sebastian and Will. From this result, we set out to test whether groups are equitable if the female students are the most in charge of their groups. Indeed, the equitable groups all had female group members with the highest inchargeness. As we discussed in the results, however, Group I1 showed that even when a female student, Paola, was the most in charge, the group was still inequitable. This result indicates that there does not seem to be a connection between the gender of the student most in charge and the level of equity in the group. Future work will explore whether other variables, such as self-efficacy [22], sense of belonging, communication styles [23], perceived similarities [24], or even individual and group extraversion [25], interact with inchargeness and group equity. Moreover, ethnicity or race can be another factor that plays a role in students' engagement in group work, thus future study should look at the interaction between gender and race.

Our study is limited by the sample size and the cases selected. As described in our methods, we deliberately sought cases to disprove our tentative claims before settling on the claims presented here. In the future, we will analyze more cases to understand if our contradictory cases are simply outlying data points. Our sample was also focused on a relatively select sample of students, namely prospective physics majors and minors with only $20 \%$ women in the course and an entirely male teaching team. Future work should evaluate whether the claims hold in courses for non-physics majors and with more visible representation of women.

\section{CONCLUSIONS}

We developed a methodology to code student interactions, specifically their bid exchanges, to characterize equitable groups in light of inchargeness. We presented evidence for two claims. First, lab groups where one student is clearly in charge can still be equitable as long as each member's opinions are heard and acknowledged by others. Second, gender and inchargeness do not seem to sufficiently predict the equity of these lab groups. The more nuanced results of equity in groups with two female students and one male student suggest that more observations must be conducted on lab groups with the same gender composition. We also plan to make other observations on groups with different gender compositions, such as all-male and all-female groups, to refine and strengthen our analysis of whether and how gender and inchargeness affect levels of equity in these groups.

\section{ACKNOWLEDGEMENTS}

This material is based upon work supported by the National Science Foundation under Grant No. 1836617. 
[1] K. N. Quinn, K. L. McGill, M. M. Kelley, E. M. Smith, and N. Holmes, in Physics Education Research Conference 2018, edited by A. Traxler, Y. Cao, and S. Wolf (Washington, D.C., 2018).

[2] K. N. Quinn, M. M. Kelley, K. L. McGill, E. M. Smith, Z. Whipps, and N. G. Holmes, Phys. Rev. Phys. Educ. Res. 16, 010129 (2020), URL https://link.aps.org/doi/10.1103/ PhysRevPhysEducRes.16.010129.

[3] D. Doucette, R. Clark, and C. Singh, European Journal of Physics 41, 035702 (2020).

[4] P. Heller and M. Hollabaugh, American Journal of Physics 60, 637 (1992).

[5] R. A. Engle, J. M. Langer-Osuna, and M. McKinney de Royston, Journal of the Learning Sciences 23, 245 (2014), ISSN 1050-8406, URL http://www.tandfonline.com/doi/abs/ 10.1080/10508406.2014.883979.

[6] B. A. Archibeque, M. B. Kustusch, F. Genz, S. Franklin, and E. C. Sayre, in International Society of the Learning Sciences (2018).

[7] S. E. C. . F. S. Kustusch, M. B., in International Society of the Learning Sciences (2018).

[8] R. Haaré and L. Van Langenhove, Positioning theory: Moral contexts of international action (Wiley-Blackwell, Oxford, UK, 1998).

[9] A. T. Danielsson and C. Linder, Gender and Education 21, 129 (2009), ISSN 0954-0253, URL http://www.tandfonline.com/ doi/abs/10.1080/09540250802213081http://www.tandfonline. com/doi/pdf/10.1080/09540250802213081.

[10] A. T. Danielsson, Gender and Education 24, 25 (2012), ISSN 0954-0253, URL http://www.tandfonline.com/doi/abs/10. 1080/09540253.2011.565040http://www.tandfonline.com/doi/ pdf/10.1080/09540253.2011.565040.

[11] I. Rodriguez, E. Brewe, V. Sawtelle, and L. H. Kramer, Physical Review Special Topics - Physics Education Research 8, 020103 (2012), ISSN 1554-9178, URL https://link.aps.org/doi/ 10.1103/PhysRevSTPER.8.020103.

[12] I. Esmonde, Review of Educational Research 79, 1008 (2009).

[13] T. Huynh, A. P. Jambuge, H. Khong, J. T. Laverty, and E. C. Sayre, Positioning in groups: The roles of expertise and being in charge (2020), 2003.01529.

[14] E. Deitrick, R. B. Shapiro, and B. Gravel (International Society of the Learning Sciences, Inc., Singapore, 2016).

[15] B. A. Archibeque, M. B. Kustusch, F. Genz, S. Franklin, and E. C. Sayre, in Physics Education Research Conference 2017, edited by A. Traxler, Y. Cao, and L. Ding (Cinncinati,OH, 2017).

[16] S. J. Basu, A. B. Barton, N. Clairmont, and D. Locke, Cult. Stud. of Sci. Educ. 4, 345 (2009).

[17] M. S. Mast, Human Communication Research 28, 420 (2002).

[18] J. A. Bianchini, Journal of Research in Science Teaching 34, 1039 (1996).

[19] J. P. Adams, G. Brissenden, R. S. Lindell, T. F. Slater, and J. Wallace, Astronomy Education Review 1, 25 (2001).

[20] K. D. Tanner, Cell Biology Education 12, 322 (2013), ISSN 1931-7913, URL http://www.lifescied.org/cgi/doi/10. 1187/cbe.13-06-0115.

[21] N. Dasgupta, M. M. Scircle, and M. Hunsinger, Proceedings of the National Academy of Sciences of the United States of America 112, 4988 (2015), ISSN 1091-6490, URL http://www.ncbi.nlm.nih.gov/pubmed/25848061http://www. pubmedcentral.nih.gov/articlerender.fcgi?artid=PMC4413283.

[22] P. L. McLeod and A. Orta-Ramirez, Journal of Food Science Education 17, 14 (2018), ISSN 15414329, URL http: //doi.wiley.com/10.1111/1541-4329.12128.

[23] E. Harskamp, N. Ding, and C. Suhre, Educational Research 50, 307 (2008), ISSN 0013-1881, URL http://www. tandfonline.com/doi/abs/10.1080/00131880802499688http:// www.tandfonline.com/doi/pdf/10.1080/00131880802499688.

[24] K. W. Phillips, G. B. Northcraft, and M. A. Neale, Group Processes \& Intergroup Relations 9, 467 (2006), ISSN 1368-4302, URL http://journals.sagepub.com/doi/10. $1177 / 1368430206067557$.

[25] G. J. Lemoine, I. Aggarwal, and L. B. Steed, The Leadership Quarterly 27, 470 (2016). 